\title{
The Role of Social Media in Intercultural Adaptation: A Review of the Literature
}

\author{
Basim Alamri ${ }^{1}$ \\ ${ }^{1}$ English Language Institute, King Abdulaziz University, Jeddah, Saudi Arabia \\ Correspondence: Basim Alamri, English Language Institute, King Abdulaziz University, Jeddah, Saudi Arabia.
}

Received: September 17, 2018 Accepted: November 10, 2018 Online Published: November 14, 2018

doi: $10.5539 /$ elt.v11n $12 \mathrm{p} 77$

URL: https://doi.org/10.5539/elt.v11n12p77

\begin{abstract}
As international students, sojourners, and immigrants arrive at host cultures, they usually employ certain means and strategies to adjust to the traditions and norms in these cultures. The present article provides a review of the literature about the impact that social networking sites (SNSs), as one of these strategies, have on the process of intercultural adaptation. The article also points out the definitions and several types of SNSs and a number of common models of intercultural adaptation. The literature shows that SNSs have been used for several purposes during the intercultural adaptation process such as: (1) to remain in contact with their family members and friends in their home countries, (2) to obtain social capital, and (3) to socially adjust in educational settings. The pedagogical implications derived from the literature are manifested in threefold: connections and relationships, community, and acculturation.
\end{abstract}

Keywords: intercultural adaptation, adjustment, social networking sites (SNSs), social media

\section{Introduction}

Newcomers to foreign cultures have implemented various technologies to help them in the cultural adaptation and acculturation process. In recent years, the most common and useful techniques utilized by the newcomers is social media, which plays a pivotal role in connecting people around the globe together in order to share and exchange knowledge and cultural traditions. In fact, the world has become a smaller village after the merging of social media applications. Therefore, people not only can interact and communicate with each other via social media sites, but they can gain information about others' society. Consequently, people from each culture can understand and respect others' unique traditions and norms.

The term intercultural adaptation refers to the adjustment of various behaviors to decrease the probability of being misunderstood when speaking and dealing with a person from a different culture (Cai \& Rodríguez, 1996). During the process of intercultural adaptation, people use social media for several purposes such as to learn about others' cultures and countries, build relationships with friends and classmates, and keep informed about events related to their cultures. In other words, interaction and communication via the Internet influence the way how social media impacts intercultural adaptation for newcomers to host countries, such as international students.

The present article provides a review of the current literature on the impact of social media on the intercultural adaptation process. The paper further reviews how social media can help international students cope with the cultural and educational adaptation process when being in a new culture for various purposes, mainly to obtain a university degree. In fact, there are different approaches and strategies that every individual uses to overcome cultural barriers, such as cultural shock. The article intends to answer the following questions:

1). How do social networking sites (SNSs) influence the process of intercultural adaptation?

2). What are some pedagogical implications of SNSs on the process of intercultural adaptation?

In the following sections, the paper starts by highlighting some important terms and definitions related to intercultural adaptation and SNSs, followed by the review of literature about the effect of SNSs on the development of intercultural adaptation. The paper concludes by providing pedagogical implications to help teachers and international students acculturate when they go abroad for different purposes. The implications are also helpful for organizations in order to prepare their employees for acculturation. 


\section{Methodology of Review}

I conducted a comprehensive and systematic review of literature to identify relevant primary sources relating to the role of social networking sites in the intercultural adaptation process. A number of published articles in peer-reviewed journals from related disciplines were identified through several procedures. First, I made a list of keywords, databases, and journals that could provide accurate results. With one exception (Sawyer, 2011), I searched for only peer-reviewed articles on the following databases: ERIC, Science Direct, EBSCO, Google Scholar. I used various keywords such as (1) intercultural + adaptation, (2) cross-cultural, (3) impacts, (4) adjustment, (5) social network sites (SNSs), (6) social media, (7) Facebook + adaptation/adjustment, (8) Twitter + adaptation, and (9) YouTube + adaptation.

As the technology evolves rapidly, I arbitrarily set the cut-off date for articles to be considered recent to 2010 . The search for primary peer-reviewed research articles yielded a list of the journals that deal with intercultural adaptation studies, such as Journal of Intercultural Communication Studies, Journal of International and Intercultural Communication, Intercultural Communication, International Journal of Intercultural Relations, and Journal of Intercultural Communication Research, to name a few.

\section{Intercultural Adaptation}

The experiences of individuals, who successfully moved from one culture and merged to another, has enriched the multicultural world (Kim, 2001). That is, the term intercultural adaptation refers to the situation when a person enters into a new culture, he or she may first enter into a state of "disequilibrium"; after a while, the individual would find the balance (Kim, 2001). Being at this status is natural since the individual does not have, or at least know, little information about the new culture. The adaptation to a new culture is a "dynamic process by which individuals, upon relocating to an unfamiliar cultural environment, establish (or reestablish) and maintain a relatively stable, reciprocal, and functional relationship with the environment" (Gudykunst, 2003, p. 244).

Adjustment to a new culture involves experiencing many factors in the processes of adaptation, such as behavioral and psychological changes because people from diverse cultures interact with each other in different manners (Kim, 2005). According to Lee, Kim, Lee, and Kim (2012), individuals need to apply adaptive skills and explore knowledge about the new culture when engaging inside the targeted culture. This process encompasses possessing an apparent awareness of one's culture and the new cultures in terms of differences and similarities. For instance, being a curious and openness person to cultural differences helps with the development of intercultural competence. Moreover, communication is essential in this intercultural process, in which communicating with people in the new culture is highly beneficial to break the barriers first, and then to adjust gradually to the new culture. Most of these skills, however, are difficult to teach, and it is the individual's responsibility to learn and discover these skills, especially in the first few days of arrival at the place of the new culture.

Regarding psychological factors, emotions have a significant impact on the process of cultural adjustment. According to Matsumoto, Hirayama, and LeRoux (2006), "[e]motional regulation allows individuals to engage in clear thinking about intercultural incidents without retreating into psychological defenses." In other words, if individuals cannot control their emotions, they may encounter difficulties in successfully accomplishing the process of adapting into new cultures. Therefore, individuals should control their emotions in order to adapt smoothly and easily to the host culture.

\subsection{Models of Intercultural Adaptation}

To illustrate the process of adapting to a new culture, five models have been discussed in the literature of studying intercultural adaptation: the recuperation model, the learning model, the recovery model, the dynamic tension reduction model, and the dialectical model (Anderson, 1994; Chen, 2013; Chen \& Starosta, 2005).

\subsubsection{The Recuperation Model}

The recuperation model is explained through the study of "culture shock" phenomenon (Oberg, 1960). The term culture shock refers to a type of anxiety occurs to an individual when he or she arrives at a new culture (Oberg, 1960). The period of this kind of anxiety ends when the individual feels comfortable. In this model, a sojourner needs to recover from culture shock to adapt successfully to the new culture. As seen in Lysgaard's (1955) U-shaped curve in Figure 1, the adaptation process begins by the honeymoon stage, where sojourners experience the new life in the host culture. Then, the sojourners fall into the crisis stage (i.e., culture shock). Once the sojourners overcome the culture shock in a certain amount of time, they can move up to the third stage (i.e., recovery) in the U-curve by adjusting gradually to the top of the U-curve until reaching the state of full 
adjustment in the host culture, in which the sojourner can adequately function in the new culture (Chen, 2013).

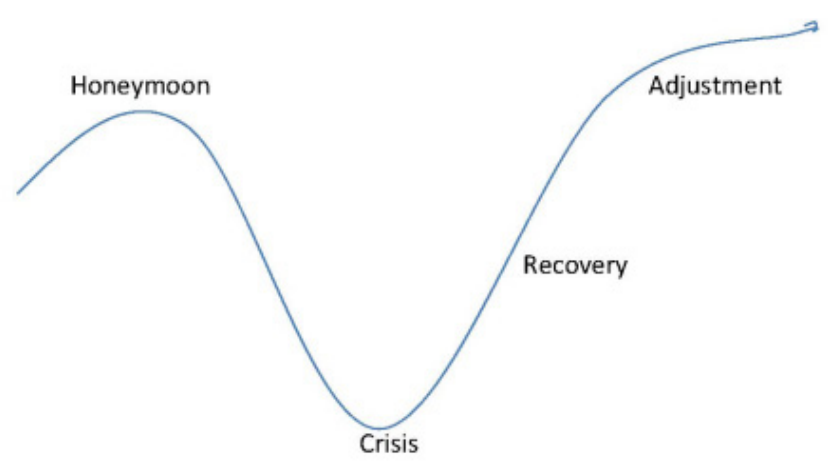

Figure 1. Lysgaard's (1955) U-shaped curve

\subsubsection{The Learning Model}

The learning model indicates that intercultural adaptation is a process of understanding and learning the sociocultural traditions and norms of the host culture, such as perceptual and behavioral rules. That is, three main factors are involved in the process of achieving intercultural communication competence: intercultural sensitivity, intercultural awareness, and intercultural effectiveness (Chen, 2010). From the social learning theory perspective, learning behavioral and perceptual rules and the norms of the new environment are important in the model (Triandis, 1980). Communication advocates, however, emphasize that new comers need to acquire verbal and nonverbal communication skills in order to become more effective in interacting with people in the new culture (Chen, 2010; Gudykunst \& Hammer, 1987).

\subsubsection{The Recovery Model}

The third model is the recovery model, in which the intercultural adaptation process of individuals centers on "a step-by-step psychological journey from the fringes to the center of a foreign culture, [and] from a state of denial or ignorance to a state of understanding and empathy" (Anderson, 1994, p. 295). A typical example of this model is the Lysgaard's (1955) U-shaped curve process. Also, Bennett's (1986) developmental model of intercultural adaptation is another example, in which intercultural sensitivity development "moves from an ethnocentric stage to the final stage of ethnorelativity" (Chen, 2010, p. 2).

\subsubsection{The Dynamic Tension Reduction Model}

The dynamic tension reduction model considers intercultural adaptation as a dynamic process of uncertainty or tension reduction. According to Cheng (2010), this model proposes that "[t]he equilibrium state of the sojourners' mental system begins to face the challenge or leads to disruption when they encounter the new cultural elements of the host culture" (p. 2). This kind of experience may result in some tension and uncertainty. Therefore, the sojourners tend to overcome this tension by developing certain techniques to cope with the internal imbalance. Torbiorn's (1982) subjective adjustment model is an example of this approach. Torbiorn argued that the more the sojourners have satisfied perceptions of the experiences in the host culture, the more the sojourners feel equilibrium and can attain the goal of international adaptation, and vice versa.

\subsubsection{The Dialectical Model}

The dialectical model views the intercultural adaptation process as a cyclic and recursive process. In this model, sojourners aim to solve some emerged issues resulted from the interaction with people in the new culture (Chen \& Starosta, 2005). Anderson (1994) asserted that every cycle of the problem-solving represents a sense of "rebirth" to the sojourner in the process of intercultural adaptation. Here, the sojourners are forced to learn how to adapt to the host culture through the development of problem-solving strategies. The model integrates several aspects from previous intercultural adaptation approaches in terms of how the sojourners develop problem-solving strategies to tackle obstacles during the cyclic process of intercultural adaptation.

\section{Social Networking Sites (i.e., Social Media)}

Nowadays, people all over the world employ social media to serve various purposes. For example, social media 
are useful to connect people and allow them to know each other. Also, people can learn about others' culture, in that they can use the Internet extensively for this purpose. In the Internet, several online communications promote interactive conversations to build understanding of different perceptions and opinions. In the realm of social media, everyone is a publisher, and everyone is a critic. That is, everyone owns an account in one of the social media applications, so that he or she shares thoughts, opinions, and criticizes whatever he or she wants.

Researchers use various terms to refer to social networking sites, such as internet social networking, social websites, social networking services, and social media. Social media refers to "a group of Internet-based applications that build on the ideological and technological foundations of Web 2.0, and that allow the creation and exchange of user-generated content" (Kaplan \& Haenlein, 2010, p. 61). In addition, social networking sites (SNSs) are "web-based services that allow individuals to (1) construct a public or semi-public profile within a bounded system, (2) articulate a list of other users with whom they share a connection, and (3) view and traverse their list of connections and those made by others within the system" (Boyd and Ellision, 2007, p. 211). SNSs offer on- and offline social interactions and communication tools among people around the world to establish and maintain relationships (Rui \& Wang, 2015). SNSs also provide users an instrument to be used by the users, for the users, and to the users. Slot and Frissen (2007) identified five categories of user roles in the world of Web 2.0: consuming, creating, sharing, facilitating, and communicating.

According to Boyd and Ellison (2008), SixDegrees.com was the first social networking site launched in 1997 that provided the ability to create profiles and communicate with friends. As can be seen in Figure 2 by Miriam (2017), several SNSs have emerged to provide the functions mentioned early as well as additional features, such as sharing live videos and exchanging messages with various online groups in different online platforms and applications. The most famous social media applications are Facebook, Twitter, and YouTube.

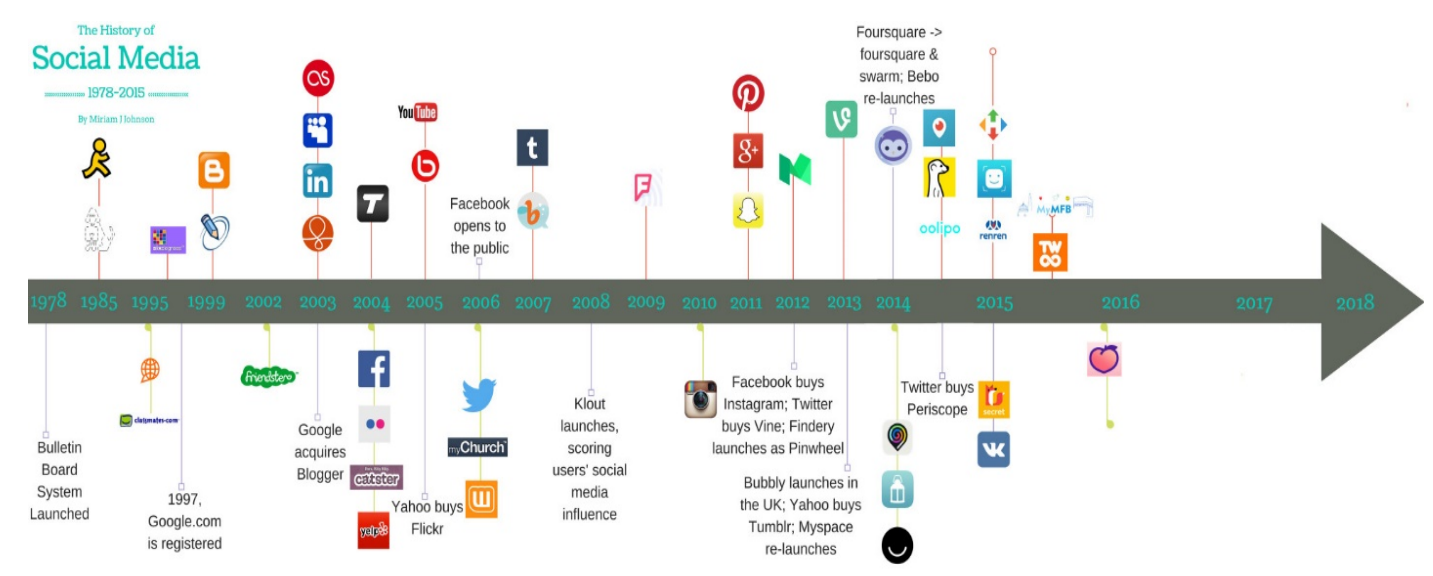

Figure 2. Timeline of Social Networking Sites (Miriam, 2017)

Facebook is the most common application in the kingdom of social media. Mark Zuckerberg created Facebook in 2004 to encourage interaction between people from various cultures around the world. Facebook (2018) has provided recent statistics about Facebook users and usages. For example, there are 1.47 billion daily active users on average for June 2018, and 2.23 billion monthly active users on Facebook as of June $30^{\text {th }}, 2018$. Officially stated,

"Facebook's mission is to give people the power to share and make the world more open and connected. People use Facebook to stay connected with friends and family, to discover what's going on in the world, and to share and express what matters to them" (Facebook, 2018).

Twitter is an online social media service that allows people to send and read short 280-character messages called "tweets", which can be used to share information about their daily activities (Java, Song, Finin, \& Tseng, 2007). "The platform was inspired by creator Tim Dorsey's introduction of an SMS-based concept that allowed members of his then-company, Odeo, to keep tabs on one another. The name 'Twitter'... is used to describe a short burst of inconsequential information" (Georgetown University, 2010). People can follow their friends, scholars, leaders, musicians, and others to stay connected with them. Twitter has influenced intercultural conversations because many people around the globe share and discuss cultural aspects of each other. Twitter has 
abridged the distance among people from different communities by providing a sort of virtual face-to-face communications and discussions with others (Sawyer, 2011).

Lastly, YouTube is a video-sharing website launched in 2005 that "allows individuals to interact with the global community by viewing and sharing user generated video content" (Georgetown University, 2010). Furthermore, YouTube allows users not only to upload, view, and share videos, but also to comment on videos and participate in discussions. Available content includes video clips, live channels, music videos, short original videos, educational videos, to name a few. Numerous people have used YouTube via computers, tablets or cellphones, and more than half of YouTube views are on mobile devices. This innovation became a great motivation for change around the world (Ostrow, 2010). YouTube has over 1.8 billion logged-in monthly users with over one billion hours watch every day, and 400 hours of video are uploaded to YouTube every minute (YouTube, 2018). The main purposes of using YouTube include entertainment, information, or persuasion.

Therefore, the main impact that social media has in cross-cultural conversations is providing a channel of communication among people for exchanging verbal or written messages. Without a doubt, people around the world can use social media not only to communicate and collaborate with others, but also to engage in debate and discussion about cultural issues regardless of the geographical distance.

\section{The Impact of Social Media on Intercultural Adaptation}

Several research studies have carried out to investigate the impact of social networking sites on the process of intercultural adaptation. These studies have revealed that international students, sojourners, and immigrants use new social media for a number of purposes along with cross-cultural acculturation. These purposes include communicating with their family members, classmates, friends, and others in both their hometowns and host countries (Hendrickson \& Rosen, 2017; Sawyer \& Chen, 2011; W. Chen, 2010; Sawyer, 2011). Other purposes are to obtain social capital (Alencar, 2018; Croucher, 2011; Naseri, 2017; Sandel, 2014), and to socially adjust in the educational settings (Ahmad, Mirza, \& Mohd, 2014; Cao \& Zhang, 2012; Forbush \& Foucault-Welles, 2016).

\subsection{The Purpose of Communicating With Friends and Families}

To explore the relationship between the Internet use and intercultural adaptation, W. Chen (2010) investigated the Internet-usage patterns of Chinese immigrants who answered a nationwide telephone survey in Singapore. The results showed that there was a relationship between the time spent in the host country and acculturation process. That is, residing in the host country for a longer time led to more interactions via social media with the host nationals, so that those immigrants acculturated quickly with the new culture. The author also found out that the use of SNSs showed an influential impact on the process of immigrants' intercultural adjustment. In other words, the social interactions of immigrants via social media could determine whether these immigrants successfully adjusted to the host country.

Correspondingly, Sawyer and Chen (2012) carried out a study to find out how social media impacted the intercultural adaptation process. The authors conducted in-depth interviews with ten international students at a university in the United States. The results emphasized that the importance of how seeking connections in social media sites impacted intercultural adaptation in overcoming adjustment challenges and establishing a sense of community with nationals.

Similarly, Sawyer (2011) investigated the usage and influence of social media on the process of intercultural adaptation of international students. The results indicated that social media helped international students establish personal relationships with people in both their home and host countries in a convenient environment, as well as nurture a sense of belonging to the host culture. Obviously, social media assisted international students to overcome cultural barriers in the intercultural adaptation process. In addition, the study revealed that the students tended to rely more on social media to stay connected with their families and friends upon arrival to the host country in order to overcome such psychological factors as cultural shock. Doing so helped the sojourners gain a kind of comfort in the new environment.

Recently, in a longitudinal mix-method investigation, Hendrickson and Rosen (2017) examined the role of SNSs and video chat applications in the development of friendship and cross-cultural adaptation. The authors surveyed 105 and interviewed 34 international students who studied in several universities in Argentina. The findings indicated that the international students employed SNSs to stay in contact with their family members and friends. The study further revealed that SNSs helped better understand local communication behaviors, in which the international students can communicate and assimilate in the intercultural adaptation process. In addition, the use of social media in the following stages moved to interact with the host nationals to help them better blend into 
the new culture.

\subsection{The Purpose of Obtaining Social Capital}

Bourdieu (1985) defined social capital as "the aggregate of the actual or potential resources which are linked to possession of a durable network of more or less institutionalized relationships of mutual acquaintance and recognition" (p. 248). In this sense, Lin, Peng, Kim, Kim, and LaRose (2011) explored the effect of SNSs on social capital and cultural adjustment of 195 international students in the United States. The findings revealed that SNSs, especially Facebook, played a significant role in building social capital, emotional adjustment, and college attachment. In a similar study, Sandel (2014) investigated students' perceptions of social media and online communication. The authors conducted in-depth interviews with 23 American and international students who were engaged in or completed a study-abroad program. The results revealed that online communication applications such as Facebook and Skype enhanced students' experiences and psychological well-being, helped with sociocultural and informational needs, and bridge relational bonds.

Recently, Alencar (2018) conducted in-depth interviews with 18 refugees from Syria, Eretria and Afghanistan who applied for asylum in Netherland. The study aimed to explore the uses and implementation of social networking sites in the cultural adaptation process. The results indicated that SNSs helped the refugees not only to acquire the language of the host country and cultural competencies, but also to bridge social capital and build bonds with friends and families in the host culture. The participants reported that they mostly used Facebook community pages to adopt to cultural norms in Netherlands along with other social media applications such as YouTube, LinkedIn, Twitter, and Instagram.

Theoretically speaking, Croucher's (2011) study sought to demonstrate a theoretical framework to explain the relationship between social media applications and cultural adaptation through the integration of cultivation theory and ethnic group vitality. The results indicated two propositions occur during cultural adaptation development. That is, SNSs will affect (1) immigrants' interaction with the dominant culture, and (2) immigrants' in-group communication.

In a review article, Naseri (2017) reviewed the former research works on the effectiveness of the Internet and SNSs, especially Facebook, on two types of social capital: bonding and bridging. The results showed that the Internet played important roles in increasing or decreasing in both types of social capital. In particular, Facebook helped broaden and strengthen relationships via creating social groups online and them meeting face-to-face, or vice versa.

\subsection{The Purpose of Socially Adjusting in the Educational Settings}

In an educational setting, Cao and Zhang (2012) investigated the correlation between SNSs and educational adaptation of Chinese international students in New Zealand. The authors used interviews to explore how the participants utilize SNSs in their adaptation process to a new educational environment. The results indicated that SNSs helped in building personal and social networks of Chinese international students to support their educational and cultural adaptation. The study also showed that the participants frequently used SNSs applications such as Renren and Facebook.

In addition, Ahmad et al. (2014) implemented Lysgaard's (1955) U-Curve model to explain the process of adaptation to a new culture. The authors conducted four focus group discussions among Malaysians who went to either Australia or United Kingdom for their education. The authors discussed students' experiences in adapting the new culture, and the role of the Internet and social media in their adaptation process. The findings showed that modern technologies kept the Malaysians students in contact with their families at home country. The students confirmed the importance of social media as a sort of support in the adaptation process.

During the initial stage of intercultural adaptation process, Forbush and Foucault-Welles (2016) explored the influence of employing SNSs on constructing social networks among 120 Chinese students in the United States. The results indicated that more utilization of SNSs led to more social and academic adaptation. In other words, the quality and types of relationships played vital significant roles compared with the quantity size of social networks.

\section{Pedagogical Implications}

The implications of social networking sites for educational and cultural purposes depend on the approaches taken by the instructors' and the students' uses and familiarity. In the era of technology, the integration of Web 2.0, and more recently Web 3.0, technology including SNSs into cultural teaching is essential, as the Internet provides students access to rich cultural resources and authentic native language use (Hong, 2013). The applications of SNSs in intercultural adjustment are manifested in threefold: connections and relationships, community, and 
adjustment

\subsection{Connections and Relationships}

Social media offer interaction and conversation platforms for international students and sojourners to help them remain in contact with local and abroad individuals from different cultural backgrounds (Rui \& Wang, 2015). SNSs are reliable and valuable sources for seeking connections during the intercultural adaptation process. Through social media, individuals can strengthen, build, and maintain relationships. Such connections and relationships assist in overcoming adjustment challenges and establishing a sense of belonging to the host community (Sawyer, 2011). Social media help students exchange various types of knowledge (Ryan, Magro, \& Sharp, 2011), and facilitate relationship development and maintenance when used as better alternatives to Face-to-Face communication (Rui \& Wang, 2015). For instance, Facebook is a tool that sojourners could use to establish friendships and to receive social support (Lee et al., 2012; Sawyer, 2011).

\subsection{Community}

Social media also influence one's sense of community while adapting to a new culture. Upon arrival to the host country, sojourners are recommended to utilize social media to establish relationships, in which they create a friendly and integrative environment to help adjust in the new culture. Simultaneously, it is essential that the international students and sojourners stay in contact with family and friends back in ones' home country. Sawyer (2011) stated that SNSs provide the opportunity for people to communicate with friends and family so that to stay updated, aware, and informed of current events. Social media sites provide resources for people who want to know how to foster and establish a kind of community and feel that they belong to multiple cultures. Ryan, Magro, and Sharp (2011) recommended instructors and professors when implementing SNSs groups in classrooms with multicultural students to establish a course-related Facebook group community, exchange various types of knowledge including cultural traditions, and encourage participation and engagement with their classmates.

\subsection{Acculturation}

According to Sawyer (2011), acculturation and adjustment are essential elements in the process of intercultural adaptation. Social media play a pivotal role in intercultural adjustment in several ways. For example, doctoral students need to employ Facebook groups to increase social capital during the transition time that happens especially at the beginning of their study programs (Magro, Ryan, Sharp, \& Ryan, 2009). In other words, social capital operates through information-giving, emotional support, and community building and enhancement to aid doctoral students. Students who recently moved to host culture have to use social media to cope with the host cultures' lifestyle and to understand cultural norms and traditions of these cultures. In short, the more sojourners employ SNSs, the better they will be able to adapt to the host country (Rui \& Wang, 2015).

\section{Conclusion and future research}

The present paper has provided a review of the current literature on the influence of social networking sites (SNSs) on the process of intercultural adaptation. The review sought to find out how international students, sojourners, or immigrants employ SNSs when they arrive at the host cultures. Several pedagogical implications were discussed to help faculty members, students, and educational organizations deal with intercultural adaptation. Future research investigations are needed in different contexts, as many of the studies have been conducted in Asia and the United States. Furthermore, other research may examine a particular application such as Instagram. In a nutshell, social media applications link people from diverse cultural backgrounds, strengthen ties and relationships with host community, and consequently improve the process of intercultural adaptation.

\section{References}

Ahmad, A. L., Mirza, E., \& Mohd, R. H. (2014). Adaptation and the new media technology: A study on Malaysian students in Australia and United Kingdom. Malaysian Journal of Communication, 30(1), 195-206. https://doi.org/10.17576/jkmjc-2014-3001-10

Alencar, A. (2018). Refugee integration and social media: A local and experiential perspective. Information, Communication \& Society, 21(11), 1588-1603. https://doi.org/10.1080/1369118X.2017.1340500

Anderson, L. E. (1994). A new look at an old construct: Cross-cultural adaptation. International Journal of Intercultural Relations, 18(3), 293-328. https://doi.org/10.1016/0147-1767(94)90035-3

Bennett, M. J. (1986). A developmental approach to training for intercultural sensitivity. International Journal of Intercultural Relations, 10. 179-196. https://doi.org/10.1016/0147-1767(86)90005-2

Boyd, D. M., \& Ellison, N. B. (2007). Social network sites: Definition, history, and scholarship. Journal of 
Computer-Mediated Communication, 13(1), 210-230. https://doi.org/10.1111/j.1083-6101.2007.00393.x

Bourdieu, P. (1985). The social space and the genesis of groups. Social Science Information, 24(2), 195-220. https://doi.org/10.1177/053901885024002001

Cai, D. A., \& Rodriguez, J. I. (1996). Adjusting to Cultural Differences: The Intercultural Adaptation Model. Intercultural Communication Studies, 1(2), 31-42.

Cao, L., \& Zhang, T. (2012). Social networking sites and educational adaptation in higher education: A case study of Chinese international students in New Zealand. The Scientific World Journal, 1-5. https://doi.org/ $10.1100 / 2012 / 289356$

Chen, G. M. (2010). A study of intercultural communication competence. Hong Kong: China Review Academic Publishers. https://doi.org/10.4018/978-1-61520-773-2.ch051

Chen, G. M. (2013). Theorizing intercultural adaptation from the perspective of boundary game. China Media Research, 9(1), 1-10. https://doi.org/10.4236/cm.2013.41001

Chen, G. M. (2015). Theorizing global community as cultural home in the new century. International Journal of Intercultural Relations, 46, 73-81. https://doi.org/10.1016/j.ijintrel.2015.03.024

Chen, G. M., \& Starosta, W. J. (2005). Foundations of Intercultural Communication. Lanham, MD: University Press of America.

Chen, G. M., \& Zhang, K. (2010). New media and cultural identity in the global society. In R. Taiwo (Ed.), Handbook of Research on Discourse Behavior and Digital Communication: Language Structures and Social Interaction (pp. 801-815). Hershey, PA: Idea Group Inc.

Chen, W. (2010). Internet use and intercultural adaptation: A case study on Chinese immigrants in Singapore. Paper presented at the annual meeting of the International Communication Association, New York City, NY.

Croucher, S. M. (2011). Social networking and cultural adaptation: A theoretical model. Journal of International and Intercultural Communication, 4(4), 259-264. https://doi.org/10.1080/17513057.2011.598046

Facebook. (2018). Statistics. Retrieved 4 July 2018 from source: http://newsroom.fb.com/company-info/

Forbush, E., \& Foucault-Welles, B. (2016). Social media use and adaptation among Chinese students beginning to study in the United States. International Journal of Intercultural Relations, 50, 1-12. https://doi.org/10.1016/j.ijintrel.2015.10.007

Georgetown University. (2010). Bridging Babel: New social media and interreligious and intercultural understanding. Retrieved November 4, 2017, from http://repository.berkleycenter.georgetown.edu //UGFNewSocialMedia.pdf.

Gudykunst, W. B. (2003). Cross-cultural and intercultural communication. Thousand Oaks, CA: Sage Publications, Inc.

Gudykunst, W. B., \& Hammer, M. R. (1987). Strangers and hosts: An uncertainty reduction-based theory of intercultural adaptation. In Y. Y. Kim, \& W. B. Gudykunst (Eds.), Cross-cultural adaptation: Current approaches (pp. 106-139). Newbury Park, CA: Sage.

Hendrickson, B., \& Rosen, D. (2017). Insights into New Media Use by International Students: Implications for Cross-Cultural Adaptation Theory. Social Networking, 6, 81-106. https://doi.org/10.4236/sn.2017.62006

Hong, Z. (2013). Social Networking Sites: Social Support, Motivation, and Influences on Chinese international students' intercultural communication competence (Doctoral dissertation).

Java, A., Song, X., Finin, T., \& Tseng, B. (2007, August). Why we twitter: understanding microblogging usage and communities. In Proceedings of the 9th WebKDD and 1st SNA-KDD 2007 workshop on Web mining and social network analysis (pp. 56-65). ACM. https://doi.org/10.1145/1348549.1348556

Kaplan, A. M., \& Haenlein, M. (2010). Users of the world, unite! The challenges and opportunities of Social Media. Business horizons, 53(1), 59-68. https://doi.org/10.1016/j.bushor.2009.09.003

Katcher, R. (1971). Culture shock: What problems in acculturation can occur in a new society? Washington DC: U.S. Department of Health, Education \& Welfare Office of Education.

Kim, Y. Y. (2001). Becoming intercultural: An integrative theory of communication and cross-cultural adaptation. Thousand Oaks, CA: Sage Publications, Inc.

Kim, Y. Y. (2005). Adapting to a new culture: An integrative communication theory. In W. B. Gudykunst (Ed.), 
Theorizing about intercultural communication (pp. 375-400). Thousand Oaks, CA: Sage. https://doi.org/ 10.1016/j.aquaculture.2005.04.073

Lee, J. W. Y., Kim, B. K., Lee, T. L., \& Kim, M. S. (2012). Uncovering the use of Facebook during an exchange program. China Media Research, 8(4), 62-76.

Lin, J. H., Peng, W., Kim, M., Kim, S. Y., \& LaRose, R. (2011). Social networking and adjustments among international students. New Media \& Society, 14(3), 421-440. https://doi.org/10.1177/1461444811418627

Lysgaard, S. (1955). Adjustment in a foreign society: Norwegian Fulbright grantees visiting the United States. International Social Sciences Bulletin, 7, 45-51.

Magro, M. J., Ryan, S. D., Sharp, J. H., \& Ryan, K. A. (2009). Using social networking for educational and cultural adaptation: An exploratory study. AMCIS 2009 Proceedings, 528.

Matsumoto, D., Hirayama, S., \& LeRoux, J. A. (2006). Psychological skills related to intercultural adjustment. In T. P. Paul, \& C. J. Lilian (Eds.), Handbook of multicultural perspectives on stress and coping (pp. 387-405). Springer, Boston, MA. https://doi.org/10.1007/0-387-26238-5_16

Miriam, J. (2017). Timeline of Social Media, 2017. Retrieved July 4, 2018, from http://www.booksaresocial.com/timeline-social-media-2017/\#lightbox/0/

Naseri, S. (2017). Online social network sites and social capital: a case of Facebook. International journal of applied sociology, 7(1), 13-19. https://doi.org/10.5923/j.ijas.20170701.02

Oberg, K. (1960). Cultural shock: adjustment to new cultural environments. Practical Anthropology, 7, 177-182. https://doi.org/10.1177/009182966000700405

Ostrow, A. (2010). YouTube is the top social media innovation of the decade. Retrieved December 4, 2017, from http://mashable.com/2009/12/22/youtube-2010/

Rui, J. R., \& Wang, H. (2015). Social network sites and international students' cross-cultural adaptation. Computers in Human Behavior, 49, 400-411. https://doi.org/10.1016/j.chb.2015.03.041

Ryan, S. D., Magro, M. J., \& Sharp, J. H. (2011). Exploring educational and cultural adaptation through social networking sites. Journal of Information Technology Education, 10(1), 1-16. https://doi.org/10.28945/1346

Sandel, T. L. (2014). "Oh, I'm Here!": Social Media's Impact on the Cross-cultural Adaptation of Students Studying Abroad. Journal of Intercultural Communication Research, 43(1), 1-29. https://doi.org/10.1080/ 17475759. 2013.865662

Sawyer, R. (2011). The impact of new social media on intercultural adaptation. Senior Honors Projects. Paper 242.

Sawyer, R., \& Chen, G. M. (2012). The Impact of Social Media on Intercultural Adaptation. Intercultural Communication Studies, 21, 151-169.

Slot, M., \& Frissen, V. (2007). Users in the 'Golden' age of the information society. Observatorio (OBS*) Journal, 1(3). 201-224.

Torbiorn, I. (1982). Living abroad: Personal adjustment and personnel policy in the overseas setting. New York: Wiley.

Triandis, H. C. (1980). A theoretical framework for the study of bilingual-bicultural adaptation. International Review of Applied Psychology, 29(1), 7-16. https://doi.org/10.1111/j.1464-0597.1980.tb00878.x

YouTube. (2018). YouTube for Press. Retrieved 4 August 2018 from https://www.youtube.com /intl/en-GB/yt/about/press/

\section{Copyrights}

Copyright for this article is retained by the author(s), with first publication rights granted to the journal.

This is an open-access article distributed under the terms and conditions of the Creative Commons Attribution license (http://creativecommons.org/licenses/by/4.0/). 